\title{
How novel structures inform understanding of complement function
}

Elena Goicoechea de Jorge ${ }^{1 \#}$, Hugo Yebenes ${ }^{2, ~ \#, ~ M a r i n a ~ S e r n a ~}{ }^{2}$, Agustín Tortajada ${ }^{1}$, Oscar Llorca ${ }^{2,3}$ and Santiago Rodríguez de Córdoba ${ }^{2,4, *}$.

\#) Equal contribution authors

1. Department of Microbiology I (Immunology), Complutense University School of Medicine and 12 de Octubre Health Research Institute (imas12), Madrid, Spain.

2. Centro de Investigaciones Biológicas, Consejo Superior de Investigaciones Cientificas, Madrid, Spain.

3. Structural Biology Programme, CNIO, C/ Melchor Fernández Almagro 3, 28029 Madrid, Spain.

4. Ciber de Enfermedades Raras, Madrid, Spain.

*) Correspondence to: Prof. Santiago Rodríguez de Córdoba, Centro de Investigaciones Biológicas, Ramiro de Maeztu 9, 28040 Madrid, Spain. srdecordoba@cib.csic.es

\section{Acknowledgments}

SRdeC is supported by the Spanish "Ministerio de Economía y CompetitividadFEDER" (SAF2015-66287R), the Seventh Framework Programme European Union Project EURenOmics (305608) and the Autonomous Region of Madrid (S2010/BMD2316). SRdeC is member of the "CIB intramural Program "Molecular Machines for Better Life (MACBET)". EGdeJ is supported by the Spanish "Ministerio de Economía y Competitividad-FEDER" (RYC-2013-13395 and SAF2014-52339P). OL is supported by the Spanish Ministry of Economy, Industry and Competitiveness (SAF2014-52301-R). AT and MS are supported by the Spanish "Ministerio de Economía y CompetitividadFEDER" (IJCI-2015-25222 and IJCI-2015-24388, respectively). 


\section{Summary}

During the last decade, the complement field has experienced outstanding advancements in the mechanistic understanding of how complement activators are recognized, what $\mathrm{C} 3$ activation means, how protein complexes like the $\mathrm{C} 3$ convertases and the membrane attack complex are assembled, and how positive and negative complement regulators perform their function. All of this has been made possible mostly because of the contributions of structural biology to the study of the complement components. The wealth of novel structural data has frequently provided support to previously held knowledge, but often has added alternative and unexpected insights into complement function. Here we will review some of these findings focusing in the alternative and terminal complement pathways.

Keywords: Complement, structural biology, C3IC5 convertase, complement regulators, factor $\mathrm{H}$, membrane attack complex. 


\section{A brief overview of a golden decade in complement structural biology.}

The determination of the structures of both intact C3 [1] and its activation fragment, C3b [2], were outstanding contributions by Piet Gros' laboratory that set the ground for a comprehensive description of $\mathrm{C} 3$ activation and regulation. Crucial to this were also the resolution of the structures of both $C 3 c$ and $C 3 d$ [3] as well as Factor B (FB) [4], the determination of the crystal structures of the complexes formed by cobra venom factor (CVF) with FB [5], the electron microscopy (EM) analysis of the alternative pathway (AP) C3 pro-convertase $(\mathrm{C} 3 \mathrm{bB})[6]$, the crystal structure of the AP C3 convertase $(\mathrm{C} 3 \mathrm{bBb})$ stabilized by the staphylococcal complement inhibitor (SCIN) [7] and the structures of the AP C3 pro-convertase (C3bB) and $\mathrm{C} 3$ convertase $(\mathrm{C} 3 \mathrm{bBb})$ in complex with Factor D (FD) [8]. All these contributions revealed in striking detail the different steps and conformational changes required for the assembly of the AP C3 convertase complex. The structural determination of the AP C3 convertase paved the way to understand the modulation of its activity by the complement regulatory proteins. The determination of the structure formed by C3b with the first four domains (SCR1-4) of Factor $\mathrm{H}(\mathrm{FH})$, the main fluid phase complement regulator, shed light on how $\mathrm{FH}$ binding to the convertase led to the release of the $\mathrm{Bb}$ fragment from the $\mathrm{AP} \mathrm{C} 3$ convertase (decay activity) [9] and how FH facilitates the Factor I (FI) [10] directed proteolytic inactivation of $\mathrm{C} 3 \mathrm{~b}$ to $\mathrm{iC} 3 \mathrm{~b}$ (cofactor activity). The structure of $\mathrm{C} 3 \mathrm{~b}$ and $\mathrm{C} 3 \mathrm{~d}$ in complex with the last two domains (SCR19-20) of $\mathrm{FH}$, as well as the ternary structure of FH (SCR-19-20) with C3d and a sialic acid molecule, helped uncover the nature of the specificity of $\mathrm{FH}$ for self surfaces where complement deposition has occurred [11,12]. In addition, the structures of other membrane bound complement regulators like membrane cofactor protein (MCP; CD46), decay acceleration factor (DAF; CD55) and Complement receptor 1 (CR1; CD35) bound to C3b confirmed a shared regulatory mechanism with $\mathrm{FH}$, [13], which was expected based on their common evolutionary origin. The study of the regulatory protein repertoire of the alternative pathway has been recently complemented by the EM and X-ray 
crystallography studies of the AP C3 convertase complexes with properdin, the only known physiological C3 convertase positive regulator [14,15].

The contribution of structural techniques to understand the activation of the terminal pathway, leading to the formation of the membrane attack complex have also been superlative. Early studies using EM determined the existence of pore lesions on the complement targeted membranes, that were later ascribed to the formation of the so-called Membrane Attack Complex (MAC) and presumed to work as the complement lytic component [16]. In the last few years most individual components of the MAC have been crystallized and their structures solved by X-ray crystallography, [17-20], but only with the new technological breakthroughs in cryoelectron microscopy and image processing has it become possible to determine the structure of the full MAC at high resolution. This in turn has finally allowed the complete topological description of the complex and provided deep insights into its assembly process [21].

\section{The assembly of the AP C3 convertase.}

The central event in the assembly and regulation of the AP C3 convertase is the activation of $\mathrm{C} 3$ to $\mathrm{C} 3 \mathrm{~b}$. This process is characterized by a dramatic conformational change in which the thioester-containing (TED) domain in $\mathrm{C} 3$ is relocated to a distant position close to the macroglobulin domain 1 (MG-1), opening the $\mathrm{C} 3$ structure and exposing an extensive and previously inaccessible molecular surface [2,22]. This conformational change, which in C3 is triggered by the so-called "tick-over" mechanism or by proteolytic cleavage of the $\alpha^{\prime} \mathrm{NT}$ domain, is also shared by the C3 homologs, C4 and C5. Early in complement structural research, it became clear that it was precisely this rearrangement in the $\mathrm{C} 3$ molecule that was responsible for generating a novel surface area, the location of the FB binding site.

The assembly of the AP C3-convertase, $\mathrm{C} 3 \mathrm{bBb}$, is initiated by the $\mathrm{Mg}^{2+}-$ dependent interaction between $\mathrm{C} 3 \mathrm{~b}$ (or the C3b-like molecule $\mathrm{C} 3\left(\mathrm{H}_{2} \mathrm{O}\right)$ ) and $\mathrm{FB}$, which circulates as an inactive pro-enzyme in plasma. This interaction involves both the $\mathrm{N}$ - 
terminal $\mathrm{Ba}$ and $\mathrm{C}$-terminal $\mathrm{Bb}$ fragments of $\mathrm{FB}$ and induces a conformational change to an open state FB that can in turn be recognized by the inactive pro-enzyme form of the protease FD. Notably, this interaction activates FD through the release of its autoinhibitory loop and the active FD then proceeds to cleave FB. After the specific proteolysis of $\mathrm{FB}$, the $\mathrm{Ba}$ fragment is released from the complex, and the active $\mathrm{C} 3 \mathrm{bBb}$ convertase is formed [8]. The $\mathrm{C} 3 \mathrm{bBb}$ convertase is an unstable bimolecular complex with a short half-life, measured at 90 seconds [23]. The extremely low affinity of the $\mathrm{Bb}$ fragment for $\mathrm{C} 3 \mathrm{~b}$ ensures that the $\mathrm{C} 3$ convertase disassembly is irreversible.

Later on, it was shown that the novel surface area exposed during the activation of $\mathrm{C} 3$ and generation of the C3b molecule is also the site where the complement regulators bind to $\mathrm{C} 3 \mathrm{~b}$ to control the decay of the AP C3 convertase and to mediate the proteolytic inactivation of C3b.

\section{A structural view to the functional differences between complement regulators}

Regulation of the AP C3 convertase is designed either to provide increased stability to the $\mathrm{C} 3 \mathrm{bBb}$ complex thereby enhancing activity, or to accelerate its decay. Structural studies have shown that activity of the "negative" regulators FH, DAF, MCP or CR1 involves interaction with a surface area in C3b that overlaps the surface that mediates the interaction with FB. In contrast, the activity of properdin stabilizing the $\mathrm{C} 3 \mathrm{bBb}$ complex requires its interaction with a different $\mathrm{C} 3 \mathrm{~b}$ region, involving the $\mathrm{C} 345 \mathrm{C}$ domain (discussed in more detail in the next subheading).

The crystal structure of C3b complexed with the first four domains (SCR1-4) of $\mathrm{FH}$ provided the molecular basis for understanding the two regulatory mechanisms, cofactor activity and decay-accelerating activity (DAA), by which the complement regulators inactivate complement activation and protect host cells [9]. The C3b-FH (SCR1-4) structure revealed a large and discontinuous interface with four contact regions throughout SCR domains 1 to 4 , with each domain establishing contacts with the C3b molecule. Based on the structure comparison of $\mathrm{C} 3 \mathrm{~b}-\mathrm{FH}(\mathrm{SCR} 1-4)$ and the AP 
C3 convertase, DAA seems to be mainly mediated by the two $\mathrm{N}$-terminal domains of FH (SCR1-2). These, through binding of the $\alpha^{\prime} \mathrm{NT}, \mathrm{MG} 2$ and MG6-7 domains of C3b, likely displace the $\mathrm{Bb}$ fragment from the convertase in a process mediated by electrostatic repulsions and steric hindrance [9,7]. The C3b-FH (SCR1-4) crystal structure also revealed that $\mathrm{FH}$ acts as the binding platform for the serine protease $\mathrm{FI}$ and enables the sequential cleavage of $\mathrm{C} 3 \mathrm{~b}$ via stabilization of the TED-CUB positioning with respect to the core of the C3b molecule [9]; cleavage inactivates the C3b because the fragments cannot form a convertase. Notably, the interaction between FH SCR1 and C3b seems to be particularly important for the cofactor activity as was demonstrated by the different cofactor activities of $\mathrm{FH}$ variants Val62lle (located in SCR1) [24].

Several crystal structures of complement regulators other than $\mathrm{FH}$ display a similar binding interface with C3b, although the SCRs involved vary depending on the regulator $[13,25,26]$. DAF requires SCR2-4 for DAA and MCP requires SCR3-4 for cofactor activity $[13,27,28]$. Three different SCR clusters (SCR1-3, SCR8-10 and SCR15-17) are involved in the DAA and cofactor activity of CR1 [29]. The subtle differences found in the $\mathrm{C} 3 \mathrm{~b}$ regions involved in the interactions with the regulators explain the different abilities of these proteins as regulators. For instance, in contrast to $\mathrm{FH}$, DAF and CR1, MCP does not interact with the a'NT region of $\mathrm{C} 3 \mathrm{~b}$, which explain its lack of DAA [13]. The cofactor activity of MCP, on the other hand, may be mediated in a similar way to that of $\mathrm{FH}$, as indicated by the adoption of the same rearrangement of C3b domains MG2, CUB and TED that is critical for the strong cofactor activity of these regulators [30].

The shared C3b binding patterns of the different regulators suggests that the two inhibitory mechanisms (DAA and cofactor activities) have evolved from a common C3b-regulator binding origin [13]. This is not unexpected given the common evolutionary origin of these complement regulatory proteins. Notably, it has also been suggested that regulators of the classical pathway of complement activation likely bind 
C4b through the same binding mode [31]. In fact, the three SCR clusters in CR1 involved in the binding to $\mathrm{C} 3 \mathrm{~b}$ are also implicated in the binding to $\mathrm{C} 4 \mathrm{~b}$, although displaying differential $\mathrm{C} 3 \mathrm{~b} / \mathrm{C} 4 \mathrm{~b}$ binding affinities and associated regulatory activities [32].

Pathogens have developed a wide range of evasion mechanisms to escape complement attack, and some of these mechanisms, resemble the way complement components interact in the host. Interestingly, microbial mimics of complement regulators such as the smallpox virus homolog (SPICE) and Kaposi's sarcomaassociated herpesvirus RCA homolog (Kaposica) bind in the same orientation and extended arrangement as the regulators at the binding platform on C3b $[13,30]$.

\section{Conformational flexibility of $\mathrm{C} 3$ in the assembly and regulation of the AP C3} convertase.

This mechanistic view has provided an explanation for most observations concerning AP C3 convertase assembly and regulation, but structural evidence beyond crystallography postulates a more complex scenario. Time-resolved FRET measurements using a fluorophore attached to the TED domain, structural studies of C3b using X-ray and neutron scattering and EM analyses have confirmed that C3b coexists in several conformations, and the positioning of the TED is not always adjacent to the MG ring, as it appears in the crystal structures (Fig. 1). A wealth of evidence suggests that such conformational flexibility can have a functional impact on the assembly and regulation of the AP C3 convertase.

Structural analysis combining EM and computational modeling has recently confirmed that the TED domain in C3b is ionically tethered to the macroglobulin (MG) ring [33]. Thus, ionic strength modulates the magnitude of the electrostatic forces anchoring the TED domain to the rest of the $\mathrm{C} 3 \mathrm{~b}$ molecule. These findings are consistent with previous data demonstrating the importance of the R102-E1032 salt 
bridge to maintain the interaction between the MG ring and the TED domain in C3b [34].

It seems apparent that the conformational variability of the TED in C3b is higher than previously thought, providing a structural explanation for the functional differences between two variants of C3b in the common R102G polymorphism (rs2230199) [35]. Residue R102 (C3/S) is the most common C3 allele, whereas G102 (C3/F) is a risk variant for developing age-related macular degeneration (AMD). In C3b/F, G102 does not support an ionic interaction with residue E1032 and therefore is more prone to a displacement of the TED domain than in C3b/S (R102). The larger flexibility of C3b (G102) would rationalize why this allele binds the complement regulator $\mathrm{FH}$ less efficiently than the R102 variant, causing decreased FI cofactor activity and extended C3 convertase lifetime. Several mutations in C3 have been recently described and characterized where the pathogenicity associated with these genetic variants correlates with the conformational stability of the TED domain in C3b. These facts support the idea that the relative position of the TED is a critical structural element that modulates the interaction of $\mathrm{C} 3 \mathrm{~b}$ with complement regulators [36].

The issue of the conformational flexibility of the TED domain has been especially controversial in the case of $\mathrm{iC} 3 \mathrm{~b}$, the first product of the $\mathrm{Fl}$-mediated proteolytic cleavage of $\mathrm{C} 3 \mathrm{~b}$. Whereas iC3b cannot assemble a C3 convertase, it plays important effector and signaling functions through its interaction with the complement receptors $\mathrm{CR} 1, \mathrm{CR} 2$ and $\mathrm{CR} 3$. iC3b can be further cleaved to C3dg by FI in the presence of CR1. Despite its functional relevance, there is no high-resolution structure of iC3b yet. Several electron microscopy reports described iC3b as a flexible extended molecule [37,38] (Fig. 1). On the other hand, Alcorlo et al. found that iC3b appeared in a compact conformation with the TED domain placed in a position closely resembling that found in C3 [39]. Although these latter observations correlated well with previous spectroscopic data, structural studies using hydrogen-deuterium exchange mass spectrometry strongly support a disordered CUB domain and presents iC $3 \mathrm{~b}$ mainly as 
a distorted extended molecule [40]. Hypothetically, the compact conformation of iC3b likely represents one of a multitude of possible conformations that may be enriched under certain experimental conditions. What the conformational flexibility of the TED would mean for iC3b function in vivo is still a matter of speculation, but one study has described two distinct conformations of iC3b on surfaces with differential binding to complement receptors [41].

The stability of the C3 convertase on complement-activating surfaces must be enhanced to allow complement to efficiently perform its functions in vivo. This is the role of properdin, the only positive complement regulator described to date. Initial EM studies of the properdin-C3bBb complex provided insights into the mechanisms by which properdin increases the stability of the $\mathrm{C} 3 \mathrm{~b}-\mathrm{Bb}$ interaction.

Each properdin monomer is an elongated molecule that interacts with another properdin monomer forming a vertex, and it is this vertex structure that interacts with and stabilizes $\mathrm{C} 3 \mathrm{bBb}$. The EM images suggested that the properdin vertex contacted the $\mathrm{C} 345 \mathrm{C}$ domain in $\mathrm{C} 3 \mathrm{~b}$ in the proximity of the Von Willebrand factor A (VWA) domain in the $\mathrm{Bb}$ fragment of $\mathrm{FB}$. Hence it seems that properdin physically grabs and holds together both the C3b and FB components of the C3-convertase, increasing the stability of the complex. Recent, and much more detailed, crystallographic data of the properdin-C3bBb complex fully supports the EM data [15], but the higher resolution of the crystal structure shows that properdin contacts mostly with the C345C domain and that potential contacts with the vWA will be probably much less extensive than expected.

Another important observation is that binding of properdin to $\mathrm{C} 3 \mathrm{bBb}$ increases the ratio of $\mathrm{C} 3 \mathrm{~b}$ molecules where the TED domain is repositioned. These observations have been interpreted as an additional mechanism to extend the lifetime of the C3 convertase by removing structural determinants needed for the interaction with the complement regulators $\mathrm{FH}, \mathrm{DAF}$ and $\mathrm{CR} 1$ [14]. Overall, the mobility of the TED domain in $\mathrm{C} 3 \mathrm{~b}$ adds a new layer of complexity to complement regulation, which, inevitably, 
seems to have been exploited by some pathogens to escape the host complement system. Staphylococcus aureus produces a protein, the extracellular fibrinogen-binding protein (Efb-C), which induces conformational changes in $\mathrm{C} 3 \mathrm{~b}$ that propagate through the molecule, displacing the TED domain to a position that impairs FB binding and C3 convertase assembly [42].

\section{Complement regulation differentiates self from pathogens and altered self.}

Because the continuous, low-level, spontaneous activation of C3 can trigger the AP everywhere, complement activation requires regulatory mechanisms that limit its action to the activating surface avoiding non-specific damage to host cells and preventing the consumption of its components. These regulatory mechanisms allow discrimination between pathogens, host cells and altered host cells so that the role of complement in fighting pathogens and removing cellular debris is not compromised. Complement regulation results from the collective activities of a group of plasma and membrane-bound regulatory proteins among which $\mathrm{FH}$ plays a leading role. Importantly, $\mathrm{FH}$ distinguishes host cells from pathogens by recognizing self-associated molecular patterns (SAMPs), such as glycosaminoglycan (GAG) chains, like heparin sulphates (HS) and sialic acids moieties which are ubiquitously found as part of the glycocalyx structures on mammalian tissues $[43,44]$. Variations in the composition and distribution of SAMPs, for which $\mathrm{FH}$ shows different affinities, contribute to restrict complement activation to particular sites, protecting other sites from complement damage $[45,44]$.

While the complement regulatory activities of $\mathrm{FH}$ span SCR1-4 $\left(\mathrm{FH}_{1-4}\right)$, the ability of $\mathrm{FH}$ to discriminate complement-activating surfaces resides in the regions comprising SCR6-7 $\left(\mathrm{FH}_{6-7}\right)$ and SCR19-20 $\left(\mathrm{FH}_{19-20}\right)$. Both regions can bind to GAGs, but only SCR20 contains a sialic acid binding site [45]. In addition, the $\mathrm{FH}_{19-20}$ region contains a $\mathrm{C} 3 \mathrm{~b}$ binding site that is required to target the $\mathrm{FH}$ regulatory activity to the complement-activating surface. A full-length high-resolution structure of native $\mathrm{FH}$ is 
not available yet, nevertheless, recombinant fragments of different $\mathrm{FH}$ regions spanning the full length of the $\mathrm{FH}$ molecule have been investigated and their structures either alone or in complex with ligands have been determined (reviewed in $[46,47])$. All together, these data suggest that $\mathrm{FH}$ adopts a hinge-like conformation toward the middle of the molecule. This conformation is facilitated by the compact arrangement of the central SCR10-15 domains bringing together the $\mathrm{N}$ - and C-terminal regions and allowing them to interact with distinct sites over the same C3b molecule. The proposed bend-back architecture of $\mathrm{FH}$ would also facilitate the simultaneous interaction of $\mathrm{FH}$ with additional glycans via SCR6-8, increasing the capacity of $\mathrm{FH}$ to discriminate between complement-activating surfaces $[48,47]$. The crystal structure of $\mathrm{C} 3 \mathrm{~d}-\mathrm{FH}_{19-20}$ complexes has revealed that the interaction of $\mathrm{FH}_{19-20}$ with $\mathrm{C} 3 \mathrm{~d}$ mostly involves SCR19 $[49,12]$, while SCR20 may contribute with an additional anchor point to a secondary C3b molecule [49]. Most importantly, the site in the TED domain of C3b recognized by $\mathrm{FH}_{19-20}$ is different from that recognized by the $\mathrm{FH}_{1-4}$ region, which further support the possibility that both $\mathrm{N}$-terminal and $\mathrm{C}$-terminal regions of $\mathrm{FH}$ bind simultaneously to the same C3b molecule.

Interestingly, the $\mathrm{Y} 402 \mathrm{H}$ polymorphism (rs1061170), strongly associated with the development of AMD, lies in SCR7 of FH, within the cluster of positively charged amino acids implicated in the binding of GAGs. Structural studies of a FH fragment including SCR6-8 $\left(\mathrm{FH}_{6-8}\right)$ have demonstrated the presence of multiple GAG-binding sites in this $\mathrm{FH}$ region, which is consistent with a single bound GAG molecule spanning these three SCRs [50]. These data also showed that the AMD-associated amino acid $\mathrm{H} 402$ residue is directly involved in GAG binding and suggest that switching between histidine and tyrosine at this position will change the GAG specificity. These findings, in the context of age-related alterations of retinal GAG composition help explain the association of this $\mathrm{FH}$ polymorphism with disease.

The specific recognition of SAMPs by the $\mathrm{FH}_{19-20}$, region seems to involve more sophisticated mechanisms. Notably, Barbel et al. [11] solved the crystal structure of a 
ternary complex formed by $\mathrm{FH}_{19-20}$, a sialylated trisaccharide and the $\mathrm{C} 3 \mathrm{~b}$ TED domain, proposing a mechanism for the specific recognition of the main sialic acid variant in humans, Neu5Ac, by the C-terminal region of $\mathrm{FH}$. According to this model, the sialic acid binding site, located in SCR20, only becomes accessible to the sugar after FH interacts with $\mathrm{C} 3 \mathrm{~b}$ (Fig. 2a). Thus, when $\mathrm{FH}$ interacts with the TED domain of $\mathrm{C} 3 \mathrm{~b}$, the so-called hypervariable loop in SCR20 adopts an open conformation that allows the accommodation of the sialic acid. By contrast, when $\mathrm{FH}$ is unbound, the loop, and in particular the K1188 side-chain, obstructs the access to the sialic binding site (Fig. 2a) $[51,11]$. These structural analyses identified the relevant amino acids residues in $\mathrm{FH}_{20}$ and the TED domains and showed that the key residues are highly conserved across mammals. These data have provided a structural framework that is proving extremely useful to understand the functional consequences of many disease-associated mutations identified in the genetic testing of patients with pathologies related to complement dysregulation.

The ability of $\mathrm{FH}$ to regulate complement activation on self and pathogen surfaces is modulated by the factor H-related proteins (FHRs) [52]. The FHRs are a family of five proteins (FHR-1, $-2,-3,-4$ and -5$)$ structurally similar to $\mathrm{FH}$. They lack the complement regulatory domains of $\mathrm{FH}$, but have conserved the $\mathrm{FH}$ surface recognition domains, which confers the capacity to compete with FH for binding to complementactivating surfaces. This FH antagonistic function of the FHRs is termed complement de-regulation. A remarkable characteristic of FHR-1, FHR-2 and FHR-5 is that the two $\mathrm{N}$-terminal SCRs, which are almost identical in these FHRs, include a dimerization domain [53]. This determines that these FHRs, in contrast to $\mathrm{FH}$, always circulate in plasma as dimers or tetramers [53,54]. This structural organization increases the avidity of FHR-1, FHR-2 and FHR-5 for their ligands (C3b, iC3b, C3dg and polyanions like sialic acids, glycosaminoglycans or heparin), facilitating competition with $\mathrm{FH}$. In addition, oligomerisation helps to generate a combinatorial repertoire of different FHRs, 
which may be useful to provide a fine-tuning for identification of opsonised surfaces with different carbohydrate compositions.

A critical issue regarding the postulated competitor role of the FHRs is what prevents them from inhibiting the normal function of $\mathrm{FH}$ in protecting the host cell surfaces, thus causing disease. In the case of FHR-1, there are two amino acid differences (S1191, V1197 in FH; L290, A296 in FHR-1) between the C-terminal regions of $\mathrm{FH}$ and $\mathrm{FHR}-1$. Interestingly, these differences involve two critical residues that appear sufficient to alter sialic acid recognition [11] (Fig. 2b, 2c), conferring distinct surface binding specificity to $\mathrm{FH}$ and FHR-1. In fact, functional analyses suggest that these amino acid substitutions do not inactivate the sialic acid binding site in FHR-1, but determine a change in its specificity $[55,56]$. As a whole the available data support that these two amino acid differences are sufficient to eliminate the risk of an undesirable competition between FH and FHR-1 from most host tissues. This implies that competition between $\mathrm{FH}$ and the FHRs may be limited to surfaces where particular variants of sialic acid are displayed. The presence of the activated C3 fragments iC3b and C3dg, which are better ligands for some FHRs than for FH $[49,48]$, may be crucial to sustain the competition between $\mathrm{FH}$ and the FHRs at these surfaces. Additional studies are needed to define the ligands and surface specificities of the FHRs in more detail and also the conditions under which competition with $\mathrm{FH}$ occurs. This knowledge will advance our understanding of biological function of the FHRs and provide very relevant insights into the pathogenic mechanisms associated with a number of complement dysregulation disorders.

\section{C3 to C5 substrate recognition shift by the AP C3/C5 convertase}

In contrast with the precise knowledge that we have of the $\mathrm{C} 3 \mathrm{bBb}$ convertase, the structure of the C5 convertase is largely unknown. The simplest form of the C5 convertase has been shown to be the $\mathrm{C} 3$ convertase $\mathrm{C} 3 \mathrm{bBb}$, but this so-called 
monomeric C5 convertase has a very weak affinity for C5 and under physiological conditions and proteins concentrations will cleave C3 and C5 in approximately a 10000 to 1 ratio [57]. The endogenous, fully active, C5 convertase is found exclusively on surfaces. Work done during the last century showed that the clustering of additional C3b molecules around the C3 convertase increases $100-1000$ fold its affinity for C5, switching the convertase substrate specificity from C3 to C5 [58]. The molecular basis for this remains a major challenge in complement structural biology. It was initially thought that formation of active classical pathway and AP C5 convertases involved covalent-linked C3b-C3b and C4b-C3b dimers [59]. Recent experiments using C3b coated beads have shown that the covalent association between C3b molecules is not necessary and instead the critical requirement to develop C5 convertase activity is a sufficiently-dense deposition of $\mathrm{C} 3 \mathrm{~b}$ with the thioester oriented towards the surface [60]. Whether the additional C3b molecules directly interact with C5 or change the conformation of the C3 convertase subunits to increase affinity for C5 is currently unknown.

Despite these difficulties in understanding the structural organization of the C5 convertase, the structure of the staphylococcal inhibitor SCIN stabilized C3bBb convertase [7] and the C5/CVF complex [61] have provided insights into how the C3 and C5 convertase may recognize their substrates. These data, together with previously available information from disease-associated mutations and complement inhibitors $[61,62,58,63,9]$, have facilitated the structural modelling of the convertasesubstrate complexes.

In particular, dimeric complexes observed in crystals of the AP C3 convertase $(\mathrm{C} 3 \mathrm{bBb})$ stabilized with SCIN strongly suggest that the interface between the two C3b monomers in the crystal truly represents the natural binding interface between C3 and C3b molecules during C3 substrate recognition by the AP C3 convertase [7]. This binding interface involves a large surface area of $\mathrm{C} 3$ (and C3b) including the domains MG3, MG4-5 and MG6-8. The contribution of these regions to substrate recognition is 
further supported by the fact that the binding sites for the inhibitors compstatin [64], CRIg [65] and antibody S77 [66], all of which block C3 binding, map within the same area.

Notably, a deletion of two amino acids (Asp923, Gly924; 923deIDG) in the MG7 domain of C3 that does not alter the normal expression and overall structure of C3 has been shown to render it resistant to cleavage by the AP C3 convertase [62]. The deletion displaces amino acid residues on either side from their positions in the wildtype protein structure. Moreover, on the $\mathrm{N}$-terminal side of the deletion a surfaceexposed loop (residues Val916 to Ser922) has been postulated as an additional interaction site between $\mathrm{C} 3$ and $\mathrm{C} 3 \mathrm{~b}$ [62]. The mutation data indeed suggest that $\mathrm{C} 3$ and $\mathrm{C} 3 \mathrm{~b}$ would contact at this region and that it is the presence of the SCIN inhibitor that separates them in the crystal structure.

In contrast to C3b, CVF binds with high affinity to C5, which has facilitated the crystallization of the CVF-C5 complex and its structural determination [61]. C5 and CVF are arranged in a head to head orientation with the two molecules aligned in parallel. Two separated regions mediate the interaction between both. The more extensive one involves contacts between the MG5 domains of both proteins. The second area is formed between the C5 MG7 domain and the MG6 and MG7 domains of CVF [61].

As a whole the structure of the dimeric $\mathrm{C} 3 \mathrm{bBb}$ complexes stabilized by $\mathrm{SCIN}$, the C5-CVF complex and numerous other experimental observations suggest that C $3 \mathrm{~b}$ and $\mathrm{C} 4 \mathrm{~b}$ in the $\mathrm{C} 3$ and $\mathrm{C} 5$ convertases recognize both $\mathrm{C} 3$ and $\mathrm{C} 5$ in a similar way to how CVF recognizes C5. This recognition involves two separate interfaces, the MG4MG5 interface and the MG7 interface. Both regions in C3 and C5 are, in this respect, important therapeutic targets for inhibition of C3 and C5 activation. Not surprisingly, binding of most current $\mathrm{C} 3$ and $\mathrm{C} 5$ convertase inhibitors map to these regions. Among them, eculizumab, a humanized antibody against C5 [67], the first complement inhibitor of the terminal pathway approved to prevent the consequences of complement 
dysregulation in patients with paroxysmal nocturnal hemoglobinuria and atypical hemolytic uremic syndrome, binds to an epitope within the MG7 domain [68] that would cause steric hindrance of $\mathrm{C} 5$ binding to $\mathrm{C} 3 \mathrm{~b}$ in the proposed substrate recognition model [60].

\section{Assembly of the MAC generates more than a lytic pore}

Proteolytic cleavage of $\mathrm{C} 5$ by the $\mathrm{C} 5$ convertase initiates the terminal pathway of the complement system, which concludes in the assembly of the immune pore called the membrane attack complex (MAC). The MAC mediates cytotoxicity in a wide range of gram-negative bacteria, in particular Neisseria species [69]. Sublytic MAC concentrations are related to a number of cell signaling pathways including inflammasome activation [70] and proliferation [71].

Recent structural studies of the MAC by cryo-electron microscopy (Fig. 3a) [21] and cryo-electron tomography [72] have shed light on the assembly mechanism of the pore. In addition to $\mathrm{C} 5 \mathrm{~b}$, this complement effector is formed by a number of soluble proteins, named C6, C7, C8 and C9, which sequentially and irreversibly assemble within cell membranes (Fig. 3b). All of the MAC components except C5b share a common architecture with a central domain called CDC/MACPF (cholesteroldependent cytolysin/membrane attack complex and perforin) and a number of auxiliary domains. The central CDC/MACPF domain contains two helical clusters responsible for membrane penetration through a major conformational change during complex assembly [73]. Upon C5b formation, C6 recognizes and binds a labile binding site in the former to create the C5b6 complex, constituting the scaffold for MAC assembly [74]. $\mathrm{C} 7$ binds to $\mathrm{C} 5 \mathrm{~b} 6$ and renders the complex lipophilic by unfurling the CDC/MACPF helical clusters into $\beta$-hairpins. The binding of $\mathrm{C} 8$ trimeric protein sets the curvature of the pore wall and regulates the binding of $\mathrm{C9}$, the last component of the MAC. C9 is the main constituent of the immune pore since it oligomerizes with up to 18 subunits aligning following the geometrical template set by C8. The MAC structure 
reveals an important role of the auxiliary domains of the MAC components in establishing specific subunit interactions and holding the complex together [21].

Productive MAC assembly necessarily has to be initiated near the membraneattached C5 convertase so that MAC precursors can quickly find a nearby membrane $[75,74]$. This could be facilitated by the existence of transient pre-activation interactions that would keep them nearby so they are immediately accessible for complex assembly [76]. Moreover, it has been proposed that C7 binding to C5b6 could drive the release of the latter from the C5 convertase [77], thus keeping the MAC precursor close to the target membrane until $\mathrm{C} 7$ binding allows membrane penetration. Another important factor in MAC assembly dynamics is that this process is also time controlled through the half-lives of some intermediates, which varies significantly. In this way, cleavage of C5 induces a protein domain reorganization exposing the C6 binding site, which is exceedingly labile, with a half-life of about 2 minutes [78,79]. If $\mathrm{C} 6$ binding is accomplished within this interval then MAC assembly will proceed [74].

Intriguingly, the absence of any available cell membrane during this process would lead to the formation of MAC-related soluble complexes with relevance in complement activation. In particular, recruitment of the molecular chaperones clusterin and vitronectin to an off-target assembled pore turns it into a soluble complex called sC5b-9 whose membrane penetration capacity is lost [18]. The importance of this complex as a biomarker for complement activation in a number of human diseases has been proved [80-82], whereas its physiological relevance is still under discussion. It has been suggested that the sC5b-9 membrane binding activity is recovered by dissociation of the chaperones [83].

In contrast to other similar immune pores, the MAC is an asymmetric pore that shows a split-washer configuration [21,72]. This asymmetry has important biological consequences and it is notably reflected in the partial membrane penetration of the MAC precursors. Contribution to local membrane distortion by the MAC might have relevant implications in cellular signaling and suggest that the MAC could function as a 
lipid composition sensor [21,84]. In fact, there is evidence that MAC lesions are preferentially formed on lipid membrane microdomains enriched in cholesterol and diacyl glycerol $[85,84]$.

The actual MAC-mediated lysis mechanism is still a matter of controversy and newly described structural features further support the concept that the MAC is more than just an immune pore that punches holes in membranes and drives osmotic lysis $[58,84]$. Interestingly, members of the same CDC/MACPF protein family such as perforin and bacterial CDCs form both complete (ring-pores) and incomplete (arcpores) homo-oligomeric structures on target membranes that are sufficient for cell lysis $[86,87]$. Hence, it cannot be excluded that the MAC could mediate cell lysis by forming arc-pores. In fact, classic photolabelling experiments showed that formation of $\mathrm{C} 5 \mathrm{~b}-8$ and especially C5b-9 caused effective lysis in liposomes in the absence of classical MAC pores [88], hinting that complete C9 oligomerization might not be essential in that process. In this sense, it has also been found that C9 alone is able to self-oligomerize under certain in vitro conditions $[89,90]$ while MAC precursors (i.e. C5b6, C7 and C8) are obligate components for pore formation under physiological conditions. These features point out the importance of the MAC precursors in the initiation and regulation of the complex assembly rather than in membrane penetration.

The only known regulator of the MAC is a GPI-anchored protein named CD59 that constitutes the main defense against host-damage by MAC lesions. A crystal structure of the CDC Intermedilysin (ILY) bound to CD59 [91] has shed light on the CD59mediated MAC regulation. It has been shown that ILY directly competes for the MAC binding site on CD59 [92] and that CD59 intercalates ILY monomers and coordinates their oligomerization into a membrane pore [91]. Similarly, CD59 would intercalate between C8 and C9 and inhibit MAC formation by limiting the input of C9 [93,94]. Interestingly, viruses such as HIV, human cytomegalovirus and vaccinia incorporate host cell CD59 into their own viral envelopes to evade complement-mediated lysis $[95,96]$. Even though the regulation of this complement effector assembly has an 
impact on a number of important human diseases, many questions still remain to be addressed. On one side and in contrast with the CDCs, there is no identified membrane receptor that triggers MAC assembly on the cell surface. Moreover, upon enzymatic activation of $\mathrm{C} 5$, the remaining components proceed by adsorption without requiring additional cofactors.

\section{Conclusions}

The processes of complement activation and regulation, how the individual complement proteins that circulate as zymogens get activated and how they interact with other complement components to build the protein complexes that are relevant for complement biological activities have been worked out in great detail during the last decade. This mechanistic understanding has been the result of a multidisciplinary approach in which different structural biology methodologies and biochemical approaches have contributed individual frames assembling into a rather complete tridimensional movie of the whole process. We are still missing frames in that movie. Mainly those dealing with processes that involve elongated, flexible complement components, or processes that happen on the cellular surfaces, which are still difficult to tackle with the current structural biology methodologies, but we will see them solved in the near future. We have discussed here how these structural data have both provided support to previous knowledge and added alternative and unexpected insights into complement function. From different perspective, this knowledge also has an immediate educational benefit that should facilitate accessibility to complement biology by outsiders to the field. In practical terms, understanding the structural basis of complement activation and regulation has a direct impact on the interpretation of complement genetic variability that is revealed by genetic studies; in one way this is because it helps reveal the pathogenic mechanisms underlying a particular disease, in another because this mechanistic understanding of complement has become, together with functional assays, critical to categorize the disease-associated genetic variants 
unveiled by genetic testing of patients. Structural knowledge is particularly valuable for those disease-associated gene variants located in functionally relevant regions that do not impact the overall structure of the protein but may cause modifications in their functional activities. Finally, it is expected that all these novel structures will help in the discovery of novel therapeutic targets for the generation of more efficient and specific drugs to control complement dysregulation in a number of pathological situations. 


\section{Figures Legends}

Fig. 1 Structural flexibility of $C 3 b$ and iC3b.

Cartoon representing the conformational flexibility of $\mathrm{C} 3 \mathrm{~b}$ and $\mathrm{iC} 3 \mathrm{~b}$ and its potential influence in complement regulation. The TED domain can display a range of conformations around the MG ring in C3b. The TED domain attaches to the MG ring in several crystal structures, but other structural methods have characterised alternative positions for the TED domain that are believed to affect the interaction with regulators. Asterisk (*) indicates the conformation of $\mathrm{C} 3 \mathrm{~b}$ with the TED domain in close proximity to the $M G$ ring that favor the interaction with the complement regulators $\mathrm{FH}, \mathrm{MCP}$ and CR1 (depicted as a green structure with four SCRs in the figure). iC3b recapitulates some of this conformational flexibility. Adapted from Alcorlo et al. [39].

\section{Fig. 2 Structure of the sialic binding site in FH and FHR-1}

(a) Superposition of the crystal structures of FH SCR20 in the absence of ligand (green) (PDB ID: 3SW0) or in complex with C3d and sialic acid (red) (PDB ID: 4ONT). Salt bridges with the sialic acid (SA) and residue D1115 in C3b are shown as light blue circles lines. The sialic acid molecule (SA) is shown in grey-white. The displacement of residues K1188 and R1215 in both structures is indicated with an orange curved arrow. (b) Superposition of the crystal structure of SCR5 of FHR-1 in the absence of ligands (yellow) (PDB ID: 4MUC) with the previous FH SCR20 structures. (c) Molecular surface comparison of the ligand binding pocket, FH SCR20 without ligands (red), FH SCR20 in complex with C3d and sialic acid (green) and FHR-1 without ligand (yellow); sialic acid is shown in grey-white and its position maintained in all three structures for comparative purpose. The $\mathrm{FH}$ sialic acid binding pocket is partially occluded by the K1188 side-chain and seems to become accessible upon the salt-bridge formation with residue D1115 in C3d. In contrast the FHR-1 ligand-binding pocket seems to be partially accessible even in the absence of ligand.

\section{Fig. 3 Assembly of the membrane attack complex (MAC).}

(a) Cryo-EM structure of the membrane attack complex (MAC). Two views of the MAC reconstruction coloured according to complement proteins as indicated in panel $B$. Scale bar represents $5 \mathrm{~nm}$. (b) Diagram representing the MAC formation. Newly released $\mathrm{C} 5 \mathrm{~b}$ (pink) initiates the assembly of the complex and sequentially binds C6 (light blue), C7 (green), C8 (orange, red and dark blue for C8 $\alpha, C 8 ß$ and C8y 
respectively) and finally C9 (yellow). The latter component oligomerizes to complete the immune pore. sC5b9 is formed by addition of chaperones clusterin and vitronectin to an off-target MAC intermediate. Adapted from Serna et al. [21]. 


\section{References}

1. Janssen BJ, Huizinga EG, Raaijmakers HC, Roos A, Daha MR, Nilsson-Ekdahl K, Nilsson B, Gros P (2005) Structures of complement component C3 provide insights into the function and evolution of immunity. Nature 437 (7058):505-511. doi:10.1038/nature04005

2. Janssen BJ, Christodoulidou A, McCarthy A, Lambris JD, Gros P (2006) Structure of $\mathrm{C} 3 \mathrm{~b}$ reveals conformational changes that underlie complement activity. Nature 444 (7116):213-216. doi:10.1038/nature05172

3. Nagar B, Jones RG, Diefenbach RJ, Isenman DE, Rini JM (1998) X-ray crystal structure of C3d: a C3 fragment and ligand for complement receptor 2. Science 280 (5367):1277-1281

4. Milder FJ, Gomes L, Schouten A, Janssen BJ, Huizinga EG, Romijn RA, Hemrika W, Roos A, Daha MR, Gros P (2007) Factor B structure provides insights into activation of the central protease of the complement system. Nature structural \& molecular biology 14 (3):224-228. doi:10.1038/nsmb1210

5. Janssen BJ, Gomes L, Koning RI, Svergun DI, Koster AJ, Fritzinger DC, Vogel CW, Gros P (2009) Insights into complement convertase formation based on the structure of the factor B-cobra venom factor complex. EMBO J 28 (16):2469-2478. doi:10.1038/emboj.2009.184

6. Torreira E, Tortajada A, Montes T, Rodriguez de Cordoba S, Llorca O (2009) 3D structure of the $\mathrm{C} 3 \mathrm{bB}$ complex provides insights into the activation and regulation of the complement alternative pathway convertase. Proc Natl Acad Sci U S A 106 (3):882-887. doi:10.1073/pnas.0810860106

7. Rooijakkers SH, Wu J, Ruyken M, van Domselaar R, Planken KL, Tzekou A, Ricklin D, Lambris JD, Janssen BJ, van Strijp JA, Gros P (2009) Structural and functional implications of the alternative complement pathway C3 convertase stabilized by a staphylococcal inhibitor. Nat Immunol 10 (7):721-727. doi:10.1038/ni.1756

8. Forneris F, Ricklin D, Wu J, Tzekou A, Wallace RS, Lambris JD, Gros P (2010) Structures of $\mathrm{C} 3 \mathrm{~b}$ in complex with factors $\mathrm{B}$ and $\mathrm{D}$ give insight into complement $\begin{array}{lll}\text { convertase formation. } & \text { Science } 330 \text { (6012):1816-1820. }\end{array}$ doi:10.1126/science.1195821

9. Wu J, Wu YQ, Ricklin D, Janssen BJ, Lambris JD, Gros P (2009) Structure of complement fragment $\mathrm{C} 3 \mathrm{~b}$-factor $\mathrm{H}$ and implications for host protection by complement regulators. Nat Immunol 10 (7):728-733. doi:10.1038/ni.1755

10. Roversi P, Johnson S, Caesar JJ, McLean F, Leath KJ, Tsiftsoglou SA, Morgan BP, Harris CL, Sim RB, Lea SM (2011) Structural basis for complement factor I control and its disease-associated sequence polymorphisms. Proc Natl Acad Sci U S A 108 (31):12839-12844. doi:10.1073/pnas.1102167108

11. Blaum BS, Hannan JP, Herbert AP, Kavanagh D, Uhrin D, Stehle T (2015) Structural basis for sialic acid-mediated self-recognition by complement factor $\mathrm{H}$. Nature chemical biology 11 (1):77-82. doi:10.1038/nchembio.1696

12. Morgan HP, Schmidt CQ, Guariento M, Blaum BS, Gillespie D, Herbert AP, Kavanagh D, Mertens HD, Svergun DI, Johansson CM, Uhrin D, Barlow PN, Hannan JP (2011) Structural basis for engagement by complement factor $\mathrm{H}$ of C3b on a self surface. Nature structural \& molecular biology 18 (4):463-470. doi:10.1038/nsmb.2018 
13. Forneris F, Wu J, Xue X, Ricklin D, Lin Z, Sfyroera G, Tzekou A, Volokhina E, Granneman JC, Hauhart R, Bertram P, Liszewski MK, Atkinson JP, Lambris JD, Gros $P$ (2016) Regulators of complement activity mediate inhibitory mechanisms through a common C3b-binding mode. EMBO J 35 (10):1133-1149. doi:10.15252/embj.201593673

14. Alcorlo M, Tortajada A, Rodriguez de Cordoba S, Llorca O (2013) Structural basis for the stabilization of the complement alternative pathway C3 convertase by properdin. Proc Natl Acad Sci U S A 110 (33):13504-13509. doi:10.1073/pnas.1309618110

15. Pedersen DV, Roumenina L, Jensen RK, Gadeberg TA, Marinozzi C, Picard C, Rybkine T, Thiel S, Sorensen UB, Stover C, Fremeaux-Bacchi V, Andersen GR (2017) Functional and structural insight into properdin control of complement alternative pathway amplification. EMBO J 36 (8):1084-1099. doi:10.15252/embj.201696173 16. Mayer MM (1972) Mechanism of cytolysis by complement. Proc Natl Acad Sci U S A 69 (10):2954-2958

17. Aleshin AE, Schraufstatter IU, Stec B, Bankston LA, Liddington RC, DiScipio RG (2012) Structure of complement C6 suggests a mechanism for initiation and unidirectional, sequential assembly of membrane attack complex (MAC). J Biol Chem 287 (13):10210-10222. doi:10.1074/jbc.M111.327809

18. Hadders MA, Bubeck D, Roversi P, Hakobyan S, Forneris F, Morgan BP, Pangburn MK, Llorca O, Lea SM, Gros P (2012) Assembly and regulation of the membrane attack complex based on structures of C5b6 and sC5b9. Cell reports 1 (3):200-207. doi:10.1016/j.celrep.2012.02.003

19. Laursen NS, Gordon N, Hermans S, Lorenz N, Jackson N, Wines B, Spillner E, Christensen JB, Jensen M, Fredslund F, Bjerre M, Sottrup-Jensen L, Fraser JD, Andersen GR (2010) Structural basis for inhibition of complement C5 by the SSL7 protein from Staphylococcus aureus. Proc Natl Acad Sci U S A 107 (8):3681-3686. doi:10.1073/pnas.0910565107

20. Lovelace LL, Cooper CL, Sodetz JM, Lebioda L (2011) Structure of human C8 protein provides mechanistic insight into membrane pore formation by complement. J Biol Chem 286 (20):17585-17592. doi:10.1074/jbc.M111.219766

21. Serna M, Giles JL, Morgan BP, Bubeck D (2016) Structural basis of complement membrane attack complex formation. Nature communications 7:10587. doi:10.1038/ncomms10587

22. Gros P, Milder FJ, Janssen BJ (2008) Complement driven by conformational changes. Nature reviews Immunology 8 (1):48-58. doi:10.1038/nri2231

23. Pangburn MK, Muller-Eberhard HJ (1986) The C3 convertase of the alternative pathway of human complement. Enzymic properties of the bimolecular proteinase. The Biochemical journal 235 (3):723-730

24. Tortajada A, Montes T, Martinez-Barricarte R, Morgan BP, Harris CL, de Cordoba SR (2009) The disease-protective complement factor $\mathrm{H}$ allotypic variant Ile62 shows increased binding affinity for $\mathrm{C} 3 \mathrm{~b}$ and enhanced cofactor activity. Hum Mol Genet 18 (18):3452-3461. doi:10.1093/hmg/ddp289

25. Kuttner-Kondo L, Hourcade DE, Anderson VE, Muqim N, Mitchell L, Soares DC, Barlow PN, Medof ME (2007) Structure-based Mapping of DAF Active Site Residues That Accelerate the Decay of C3 Convertases. Journal of Biological Chemistry 282 (25):18552-18562. doi:10.1074/jbc.M611650200

26. Lukacik P, Roversi P, White J, Esser D, Smith GP, Billington J, Williams PA, Rudd PM, Wormald MR, Harvey DJ, Crispin MD, Radcliffe CM, Dwek RA, Evans DJ, Morgan 
BP, Smith RA, Lea SM (2004) Complement regulation at the molecular level: the structure of decay-accelerating factor. Proc Natl Acad Sci U S A 101 (5):1279-1284. doi:10.1073/pnas.0307200101

27. Harris CL, Pettigrew DM, Lea SM, Morgan BP (2007) Decay-accelerating factor must bind both components of the complement alternative pathway C3 convertase to mediate efficient decay. J Immunol 178 (1):352-359

28. Liszewski MK, Leung M, Cui W, Subramanian VB, Parkinson J, Barlow PN, Manchester M, Atkinson JP (2000) Dissecting sites important for complement regulatory activity in membrane cofactor protein (MCP; CD46). J Biol Chem 275 (48):37692-37701. doi:10.1074/jbc.M004650200

29. Krych-Goldberg M, Hauhart RE, Porzukowiak T, Atkinson JP (2005) Synergy between two active sites of human complement receptor type 1 (CD35) in complement regulation: implications for the structure of the classical pathway C3 convertase and generation of more potent inhibitors. J Immunol 175 (7):45284535

30. Gautam AK, Panse Y, Ghosh P, Reza MJ, Mullick J, Sahu A (2015) Mutational analysis of Kaposica reveals that bridging of MG2 and CUB domains of target protein is crucial for the cofactor activity of RCA proteins. Proc Natl Acad Sci U S A 112 (41):12794-12799. doi:10.1073/pnas.1506449112

31. Nonaka M, Yoshizaki F (2004) Primitive complement system of invertebrates. Immunol Rev 198:203-215

32. Krych M, Hourcade D, Atkinson JP (1991) Sites within the complement $\mathrm{C} 3 \mathrm{~b} / \mathrm{C} 4 \mathrm{~b}$ receptor important for the specificity of ligand binding. Proc Natl Acad Sci U S A 88 (10):4353-4357

33. Lopez-Perrote A, Harrison RE, Subias M, Alcorlo M, Rodriguez de Cordoba S, Morikis D, Llorca O (2017) Ionic tethering contributes to the conformational stability and function of complement C3b. Molecular immunology 85:137-147. doi:10.1016/j.molimm.2016.12.015

34. Rodriguez E, Nan R, Li K, Gor J, Perkins SJ (2015) A revised mechanism for the activation of complement $\mathrm{C} 3$ to $\mathrm{C} 3 \mathrm{~b}$ : a molecular explanation of a diseaseassociated polymorphism. J Biol Chem 290 (4):2334-2350. doi:10.1074/jbc.M114.605691

35. Heurich M, Martinez-Barricarte R, Francis NJ, Roberts DL, Rodriguez de Cordoba S, Morgan BP, Harris CL (2011) Common polymorphisms in C3, factor B, and factor $\mathrm{H}$ collaborate to determine systemic complement activity and disease risk. Proc Natl Acad Sci U S A 108 (21):8761-8766. doi:10.1073/pnas.1019338108 36. Martinez-Barricarte R, Heurich M, Lopez-Perrote A, Tortajada A, Pinto S, LopezTrascasa M, Sanchez-Corral P, Morgan BP, Llorca O, Harris CL, Rodriguez de Cordoba S (2015) The molecular and structural bases for the association of complement C3 mutations with atypical hemolytic uremic syndrome. Molecular immunology 66 (2):263-273. doi:10.1016/j.molimm.2015.03.248

37. Chen X, Yu Y, Mi LZ, Walz T, Springer TA (2012) Molecular basis for complement recognition by integrin alphaXbeta2. Proc Natl Acad Sci U S A 109 (12):4586-4591. doi:10.1073/pnas.1202051109

38. Nishida N, Walz T, Springer TA (2006) Structural transitions of complement component C3 and its activation products. Proc Natl Acad Sci U S A 103 (52):19737-19742. doi:10.1073/pnas.0609791104 
39. Alcorlo M, Lopez-Perrote A, Delgado S, Yebenes H, Subias M, Rodriguez-Gallego C, Rodriguez de Cordoba S, Llorca O (2015) Structural insights on complement activation. The FEBS journal 282 (20):3883-3891. doi:10.1111/febs.13399

40. Papanastasiou M, Koutsogiannaki S, Sarigiannis Y, Geisbrecht BV, Ricklin D, Lambris JD (2017) Structural Implications for the Formation and Function of the Complement Effector Protein iC3b. J Immunol 198 (8):3326-3335. doi:10.4049/jimmunol.1601864

41. Nilsson UR, Funke L, Nilsson B, Ekdahl KN (2011) Two conformational forms of target-bound $\mathrm{iC} 3 \mathrm{~b}$ that distinctively bind complement receptors 1 and 2 and two specific monoclonal antibodies. Upsala journal of medical sciences 116 (1):26-33. doi:10.3109/03009734.2010.528465

42. Chen H, Ricklin D, Hammel M, Garcia BL, McWhorter WJ, Sfyroera G, Wu YQ, Tzekou A, Li S, Geisbrecht BV, Woods VL, Jr., Lambris JD (2010) Allosteric inhibition of complement function by a staphylococcal immune evasion protein. Proc Natl Acad Sci U S A 107 (41):17621-17626. doi:10.1073/pnas.1003750107 43. Langford-Smith A, Day AJ, Bishop PN, Clark SJ (2015) Complementing the Sugar Code: Role of GAGs and Sialic Acid in Complement Regulation. Frontiers in immunology 6:25. doi:10.3389/fimmu.2015.00025

44. Varki A (2011) Since there are PAMPs and DAMPs, there must be SAMPs? Glycan "self-associated molecular patterns" dampen innate immunity, but pathogens can mimic them. Glycobiology 21 (9):1121-1124

45. Clark SJ, Ridge LA, Herbert AP, Hakobyan S, Mulloy B, Lennon R, Wurzner R, Morgan BP, Uhrin D, Bishop PN, Day AJ (2013) Tissue-specific host recognition by complement factor $\mathrm{H}$ is mediated by differential activities of its glycosaminoglycan-binding regions. J Immunol 190 (5):2049-2057. doi:10.4049/jimmunol.1201751

46. Lea SM, Johnson S (2012) Putting the structure into complement. Immunobiology 217 (11):1117-1121. doi:10.1016/j.imbio.2012.07.005

47. Makou E, Herbert AP, Barlow PN (2013) Functional anatomy of complement factor H. Biochemistry 52 (23):3949-3962. doi:10.1021/bi4003452

48. Kopp A, Strobel S, Tortajada A, Rodriguez de Cordoba S, Sanchez-Corral P, Prohaszka Z, Lopez-Trascasa M, Jozsi M (2012) Atypical hemolytic uremic syndrome-associated variants and autoantibodies impair binding of factor $h$ and factor h-related protein 1 to pentraxin 3. J Immunol 189 (4):1858-1867. doi:10.4049/jimmunol.1200357

49. Kajander T, Lehtinen MJ, Hyvarinen S, Bhattacharjee A, Leung E, Isenman DE, Meri S, Goldman A, Jokiranta TS (2011) Dual interaction of factor H with C3d and glycosaminoglycans in host-nonhost discrimination by complement. Proc Natl Acad Sci U S A 108 (7):2897-2902. doi:10.1073/pnas.1017087108

50. Prosser BE, Johnson S, Roversi P, Herbert AP, Blaum BS, Tyrrell J, Jowitt TA, Clark SJ, Tarelli E, Uhrin D, Barlow PN, Sim RB, Day AJ, Lea SM (2007) Structural basis for complement factor $\mathrm{H}$ linked age-related macular degeneration. The Journal of experimental medicine 204 (10):2277-2283. doi:10.1084/jem.20071069

51. Blaum BS (2017) The lectin self of complement factor H. Current opinion in structural biology 44:111-118. doi:10.1016/j.sbi.2017.01.005

52. Jozsi M, Tortajada A, Uzonyi B, Goicoechea de Jorge E, Rodriguez de Cordoba S (2015) Factor H-related proteins determine complement-activating surfaces. Trends in immunology 36 (6):374-384. doi:10.1016/j.it.2015.04.008 
53. Goicoechea de Jorge E, Caesar JJ, Malik TH, Patel M, Colledge M, Johnson S, Hakobyan S, Morgan BP, Harris CL, Pickering MC, Lea SM (2013) Dimerization of complement factor H-related proteins modulates complement activation in vivo. Proc Natl Acad Sci U S A 110 (12):4685-4690. doi:10.1073/pnas.1219260110

54. Tortajada A, Yebenes H, Abarrategui-Garrido C, Anter J, Garcia-Fernandez JM, Martinez-Barricarte R, Alba-Dominguez M, Malik TH, Bedoya R, Cabrera Perez R, Lopez Trascasa M, Pickering MC, Harris CL, Sanchez-Corral P, Llorca O, Rodriguez de Cordoba S (2013) C3 glomerulopathy-associated CFHR1 mutation alters FHR oligomerization and complement regulation. The Journal of clinical investigation 123 (6):2434-2446. doi:10.1172/JCI68280

55. Valoti E, Alberti M, Tortajada A, Garcia-Fernandez J, Gastoldi S, Besso L, Bresin E, Remuzzi G, Rodriguez de Cordoba S, Noris M (2015) A novel atypical hemolytic uremic syndrome-associated hybrid CFHR1/CFH gene encoding a fusion protein that antagonizes factor $\mathrm{H}$-dependent complement regulation. Journal of the American Society of Nephrology : JASN 26 (1):209-219. doi:10.1681/ASN.2013121339

56. Venables JP, Strain L, Routledge D, Bourn D, Powell HM, Warwicker P, DiazTorres ML, Sampson A, Mead P, Webb M, Pirson Y, Jackson MS, Hughes A, Wood KM, Goodship JA, Goodship TH (2006) Atypical haemolytic uraemic syndrome associated with a hybrid complement gene. PLoS medicine 3 (10):e431. doi:10.1371/journal.pmed.0030431

57. Rawal N, Pangburn MK (2001) Structure/function of C5 convertases of complement. International immunopharmacology 1 (3):415-422

58. Pangburn MK, Rawal N (2002) Structure and function of complement C5 convertase enzymes. Biochemical Society transactions 30 (Pt 6):1006-1010. doi:10.1042/

59. Hong K, Kinoshita T, Pramoonjago P, Kim YU, Seya T, Inoue K (1991) Reconstitution of $\mathrm{C} 5$ convertase of the alternative complement pathway with isolated C3b dimer and factors B and D. J Immunol 146 (6):1868-1873

60. Berends ET, Gorham RD, Jr., Ruyken M, Soppe JA, Orhan H, Aerts PC, de Haas CJ, Gros P, Rooijakkers SH (2015) Molecular insights into the surface-specific arrangement of complement C5 convertase enzymes. BMC biology 13:93. doi:10.1186/s12915-015-0203-8

61. Laursen NS, Andersen KR, Braren I, Spillner E, Sottrup-Jensen L, Andersen GR (2011) Substrate recognition by complement convertases revealed in the C5-cobra venom factor complex. EMBO J 30 (3):606-616. doi:10.1038/emboj.2010.341

62. Martinez-Barricarte R, Heurich M, Valdes-Canedo F, Vazquez-Martul E, Torreira E, Montes T, Tortajada A, Pinto S, Lopez-Trascasa M, Morgan BP, Llorca O, Harris CL, Rodriguez de Cordoba S (2010) Human C3 mutation reveals a mechanism of dense deposit disease pathogenesis and provides insights into complement activation and regulation. The Journal of clinical investigation 120 (10):3702-3712. doi:10.1172/JCI43343

63. Roumenina LT, Jablonski M, Hue C, Blouin J, Dimitrov JD, Dragon-Durey MA, Cayla M, Fridman WH, Macher MA, Ribes D, Moulonguet L, Rostaing L, Satchell SC, Mathieson PW, Sautes-Fridman C, Loirat C, Regnier CH, Halbwachs-Mecarelli L, Fremeaux-Bacchi V (2009) Hyperfunctional C3 convertase leads to complement deposition on endothelial cells and contributes to atypical hemolytic uremic syndrome. Blood 114 (13):2837-2845. doi:10.1182/blood-2009-01-197640 
64. Janssen BJ, Halff EF, Lambris JD, Gros P (2007) Structure of compstatin in complex with complement component $\mathrm{C} 3 \mathrm{c}$ reveals a new mechanism of complement inhibition. J Biol Chem 282 (40):29241-29247. doi:10.1074/jbc.M704587200

65. Wiesmann C, Katschke KJ, Yin J, Helmy KY, Steffek M, Fairbrother WJ, McCallum SA, Embuscado L, DeForge L, Hass PE, van Lookeren Campagne M (2006) Structure of $\mathrm{C} 3 \mathrm{~b}$ in complex with CRIg gives insights into regulation of complement activation. Nature 444 (7116):217-220. doi:10.1038/nature05263

66. Katschke KJ, Jr., Stawicki S, Yin J, Steffek M, Xi H, Sturgeon L, Hass PE, Loyet KM, Deforge L, Wu Y, van Lookeren Campagne M, Wiesmann C (2009) Structural and functional analysis of a C3b-specific antibody that selectively inhibits the alternative pathway of complement. J Biol Chem 284 (16):10473-10479. doi:10.1074/jbc.M809106200

67. Hillmen P, Young NS, Schubert J, Brodsky RA, Socie G, Muus P, Roth A, Szer J, Elebute MO, Nakamura R, Browne P, Risitano AM, Hill A, Schrezenmeier H, Fu CL, Maciejewski J, Rollins SA, Mojcik CF, Rother RP, Luzzatto L (2006) The complement inhibitor eculizumab in paroxysmal nocturnal hemoglobinuria. The New England journal of medicine 355 (12):1233-1243. doi:10.1056/NEJMoa061648

68. Brachet G, Bourquard T, Gallay N, Reiter E, Gouilleux-Gruart V, Poupon A, Watier H (2016) Eculizumab epitope on complement C5: Progress towards a better understanding of the mechanism of action. Molecular immunology 77:126131. doi:10.1016/j.molimm.2016.07.016

69. Podack ER (1984) Molecular composition of the tubular structure of the membrane attack complex of complement. J Biol Chem 259 (13):8641-8647

70. Morgan BP (2016) The membrane attack complex as an inflammatory trigger. Immunobiology 221 (6):747-751. doi:10.1016/j.imbio.2015.04.006

71. Niculescu F, Badea T, Rus H (1999) Sublytic C5b-9 induces proliferation of human aortic smooth muscle cells: role of mitogen activated protein kinase and phosphatidylinositol 3-kinase. Atherosclerosis 142 (1):47-56

72. Sharp TH, Koster AJ, Gros P (2016) Heterogeneous MAC Initiator and Pore Structures in a Lipid Bilayer by Phase-Plate Cryo-electron Tomography. Cell reports 15 (1):1-8. doi:10.1016/j.celrep.2016.03.002

73. Shepard LA, Heuck AP, Hamman BD, Rossjohn J, Parker MW, Ryan KR, Johnson AE, Tweten RK (1998) Identification of a membrane-spanning domain of the thiolactivated pore-forming toxin Clostridium perfringens perfringolysin 0: an alphahelical to beta-sheet transition identified by fluorescence spectroscopy. Biochemistry 37 (41):14563-14574. doi:10.1021/bi981452f

74. Hadders MA, Beringer DX, Gros P (2007) Structure of C8alpha-MACPF reveals mechanism of membrane attack in complement immune defense. Science 317 (5844):1552-1554. doi:10.1126/science.1147103

75. Bubeck D (2014) The making of a macromolecular machine: assembly of the membrane attack complex. Biochemistry 53 (12):1908-1915. doi:10.1021/bi500157z

76. Sandoval A, Ai R, Ostresh JM, Ogata RT (2000) Distal recognition site for classical pathway convertase located in the C345C/netrin module of complement component C5. J Immunol 165 (2):1066-1073

77. Kolb WP, Muller-Eberhard HJ (1975) The membrane attack mechanism of complement. Isolation and subunit composition of the C5b-9 complex. The Journal of experimental medicine 141 (4):724-735 
78. Cooper NR, Muller-Eberhard HJ (1970) The reaction mechanism of human C5 in immune hemolysis. The Journal of experimental medicine 132 (4):775-793

79. DiScipio RG (1981) The conversion of human complement component C5 into fragment $\mathrm{C} 5 \mathrm{~b}$ by the alternative-pathway $\mathrm{C} 5$ convertase. The Biochemical journal 199 (3):497-504

80. Brodeur JP, Ruddy S, Schwartz LB, Moxley G (1991) Synovial fluid levels of complement SC5b-9 and fragment $\mathrm{Bb}$ are elevated in patients with rheumatoid arthritis. Arthritis and rheumatism 34 (12):1531-1537

81. Chiu YY, Nisihara RM, Wurzner R, Kirschfink M, de Messias-Reason IJ (1998) SC5b-9 is the most sensitive marker in assessing disease activity in Brazilian SLE patients. Journal of investigational allergology \& clinical immunology 8 (4):239244

82. Moen O, Fosse E, Brockmeier V, Andersson C, Mollnes TE, Hogasen K, Venge P (1995) Disparity in blood activation by two different heparin-coated cardiopulmonary bypass systems. The Annals of thoracic surgery 60 (5):13171323

83. Podack ER, Muller-Eberhard HJ (1980) SC5b-9 complex of complement: formation of the dimeric membrane attack complex by removal of S-protein. J Immunol 124 (4):1779-1783

84. Stein JM, Luzio JP (1991) Ectocytosis caused by sublytic autologous complement attack on human neutrophils. The sorting of endogenous plasmamembrane proteins and lipids into shed vesicles. The Biochemical journal 274 ( Pt 2):381-386

85. Morgan BP, Walters D, Serna M, Bubeck D (2016) Terminal complexes of the complement system: new structural insights and their relevance to function. Immunol Rev 274 (1):141-151. doi:10.1111/imr.12461

86. Leung C, Dudkina NV, Lukoyanova N, Hodel AW, Farabella I, Pandurangan AP, Jahan N, Pires Damaso M, Osmanovic D, Reboul CF, Dunstone MA, Andrew PW, Lonnen R, Topf M, Saibil HR, Hoogenboom BW (2014) Stepwise visualization of membrane pore formation by suilysin, a bacterial cholesterol-dependent cytolysin. eLife 3:e04247. doi:10.7554/eLife.04247

87. Metkar SS, Marchioretto M, Antonini V, Lunelli L, Wang B, Gilbert RJ, Anderluh G, Roth R, Pooga M, Pardo J, Heuser JE, Serra MD, Froelich CJ (2015) Perforin oligomers form arcs in cellular membranes: a locus for intracellular delivery of granzymes. Cell death and differentiation 22 (1):74-85. doi:10.1038/cdd.2014.110 88. Hu VW, Esser AF, Podack ER, Wisnieski BJ (1981) The membrane attack mechanism of complement: photolabeling reveals insertion of terminal proteins into target membrane. J Immunol 127 (1):380-386

89. Saifuddin M, Hedayati T, Atkinson JP, Holguin MH, Parker CJ, Spear GT (1997) Human immunodeficiency virus type 1 incorporates both glycosyl phosphatidylinositol-anchored CD55 and CD59 and integral membrane CD46 at levels that protect from complement-mediated destruction. The Journal of general virology 78 ( Pt 8):1907-1911. doi:10.1099/0022-1317-78-8-1907

90. Spear GT, Lurain NS, Parker CJ, Ghassemi M, Payne GH, Saifuddin M (1995) Host cell-derived complement control proteins CD55 and CD59 are incorporated into the virions of two unrelated enveloped viruses. Human $\mathrm{T}$ cell leukemia/lymphoma virus type I (HTLV-I) and human cytomegalovirus (HCMV). J Immunol 155 (9):4376-4381 
91. Johnson S, Brooks NJ, Smith RA, Lea SM, Bubeck D (2013) Structural basis for recognition of the pore-forming toxin intermedilysin by human complement receptor CD59. Cell reports 3 (5):1369-1377. doi:10.1016/j.celrep.2013.04.029 92. Wickham SE, Hotze EM, Farrand AJ, Polekhina G, Nero TL, Tomlinson S, Parker MW, Tweten RK (2011) Mapping the intermedilysin-human CD59 receptor interface reveals a deep correspondence with the binding site on CD59 for complement binding proteins C8alpha and C9. J Biol Chem 286 (23):20952-20962. doi:10.1074/jbc.M111.237446

93. Biesecker G, Lachmann P, Henderson R (1993) Structure of complement polyC9 determined in projection by cryo-electron microscopy and single particle analysis. Molecular immunology 30 (15):1369-1382

94. Dudkina NV, Spicer BA, Reboul CF, Conroy PJ, Lukoyanova N, Elmlund H, Law RH, Ekkel SM, Kondos SC, Goode RJ, Ramm G, Whisstock JC, Saibil HR, Dunstone MA (2016) Structure of the poly-C9 component of the complement membrane attack complex. Nature communications 7:10588. doi:10.1038/ncomms10588

95. Farkas I, Baranyi L, Ishikawa Y, Okada N, Bohata C, Budai D, Fukuda A, Imai M, Okada H (2002) CD59 blocks not only the insertion of C9 into MAC but inhibits ion channel formation by homologous $\mathrm{C} 5 \mathrm{~b}-8$ as well as C5b-9. The Journal of physiology 539 (Pt 2):537-545

96. Meri S, Morgan BP, Davies A, Daniels RH, Olavesen MG, Waldmann H, Lachmann PJ (1990) Human protectin (CD59), an 18,000-20,000 MW complement lysis restricting factor, inhibits $\mathrm{C} 5 \mathrm{~b}-8$ catalysed insertion of $\mathrm{C} 9$ into lipid bilayers. Immunology 71 (1):1-9 


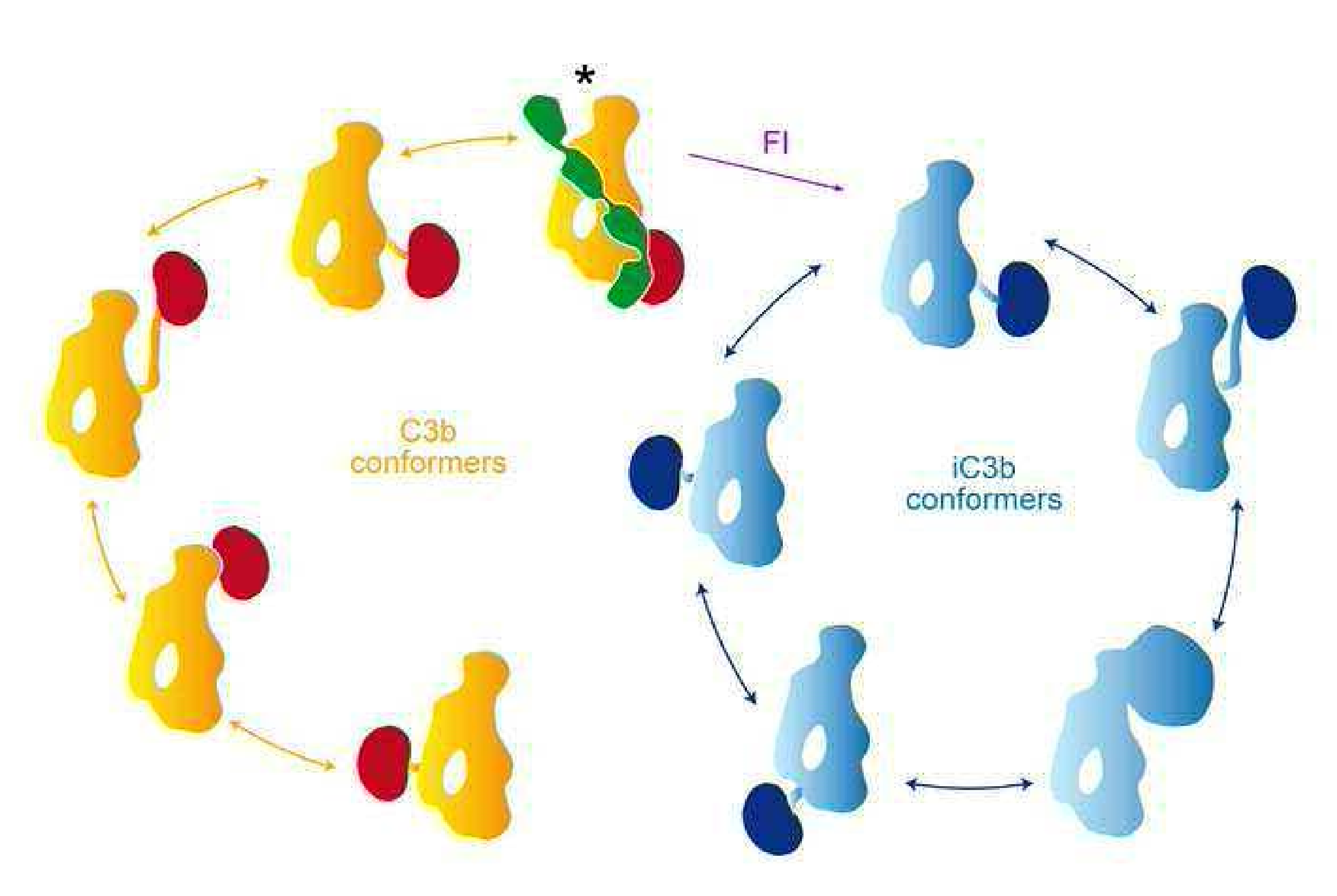


a C3b(D1115)

R1215

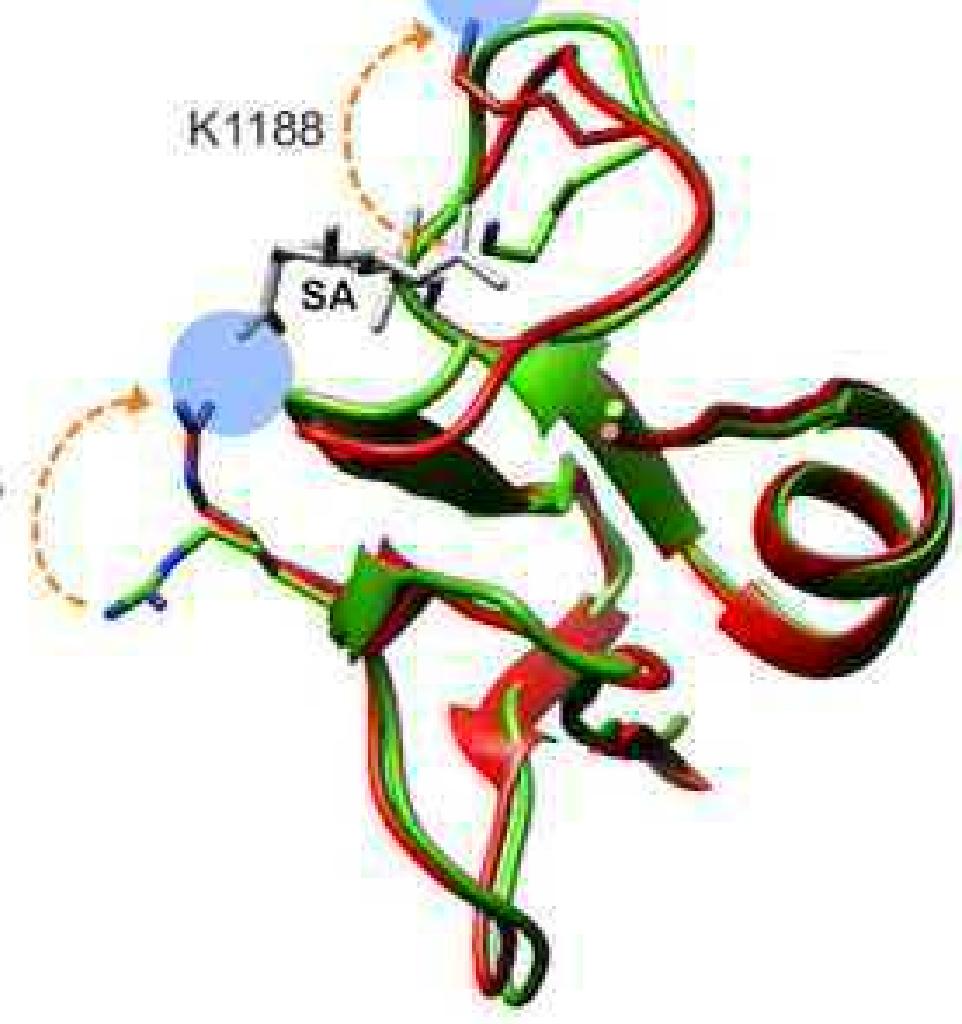

b

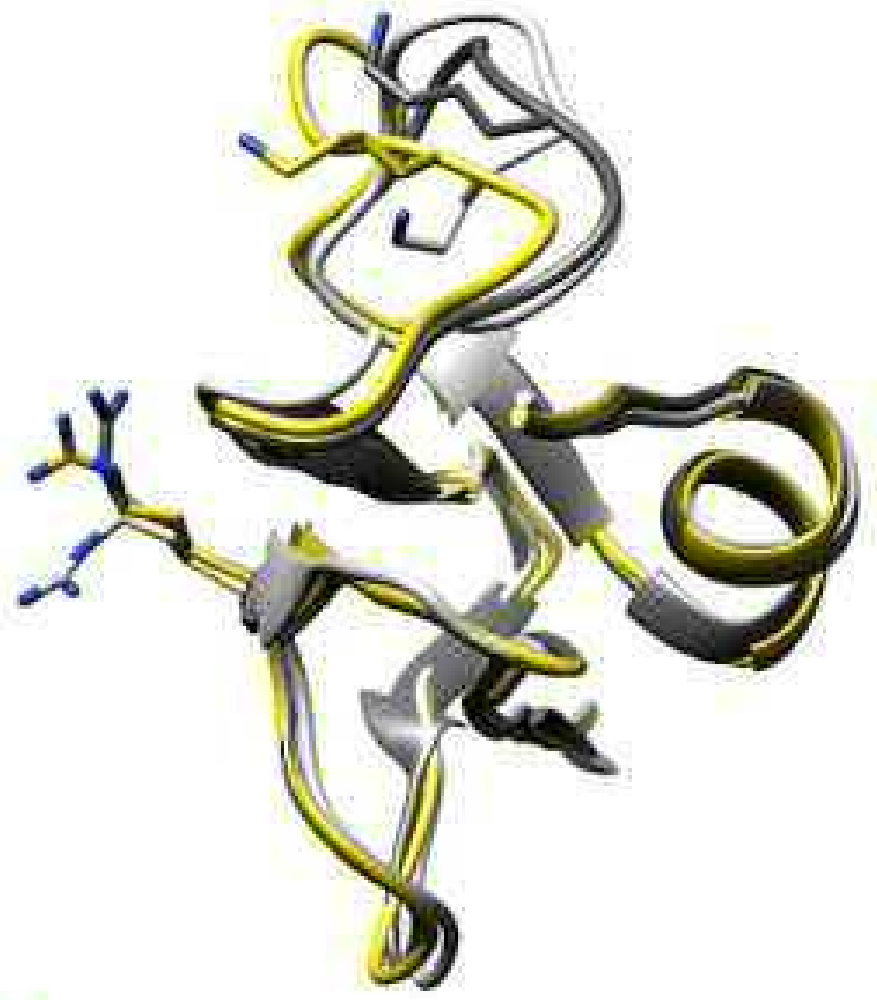

C
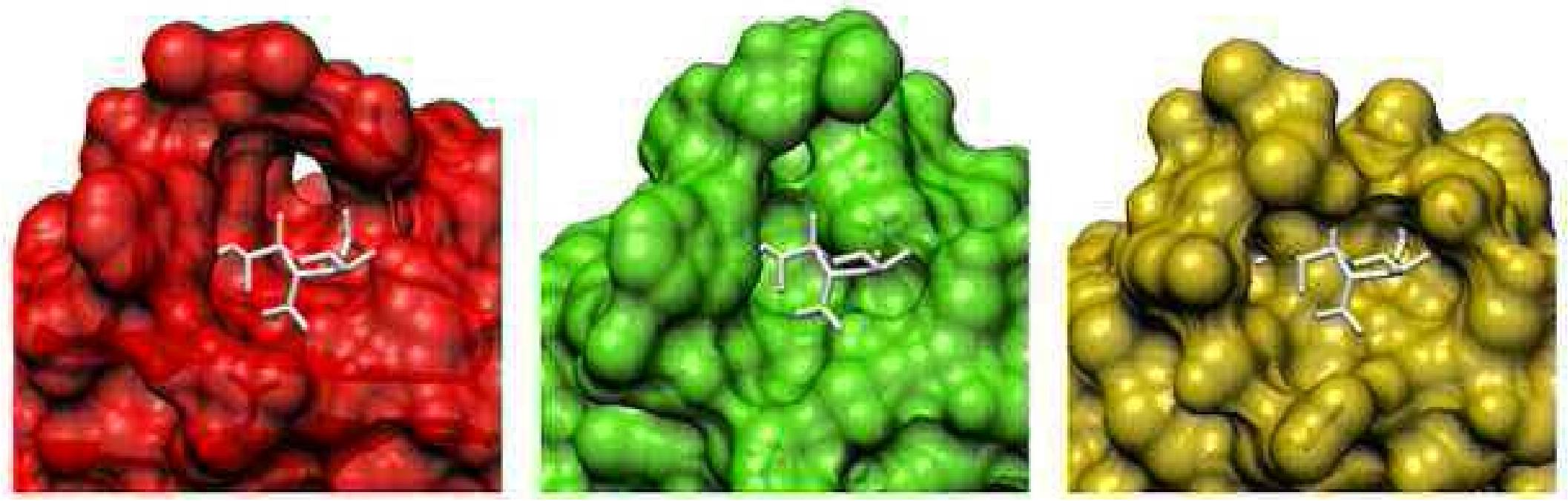
a
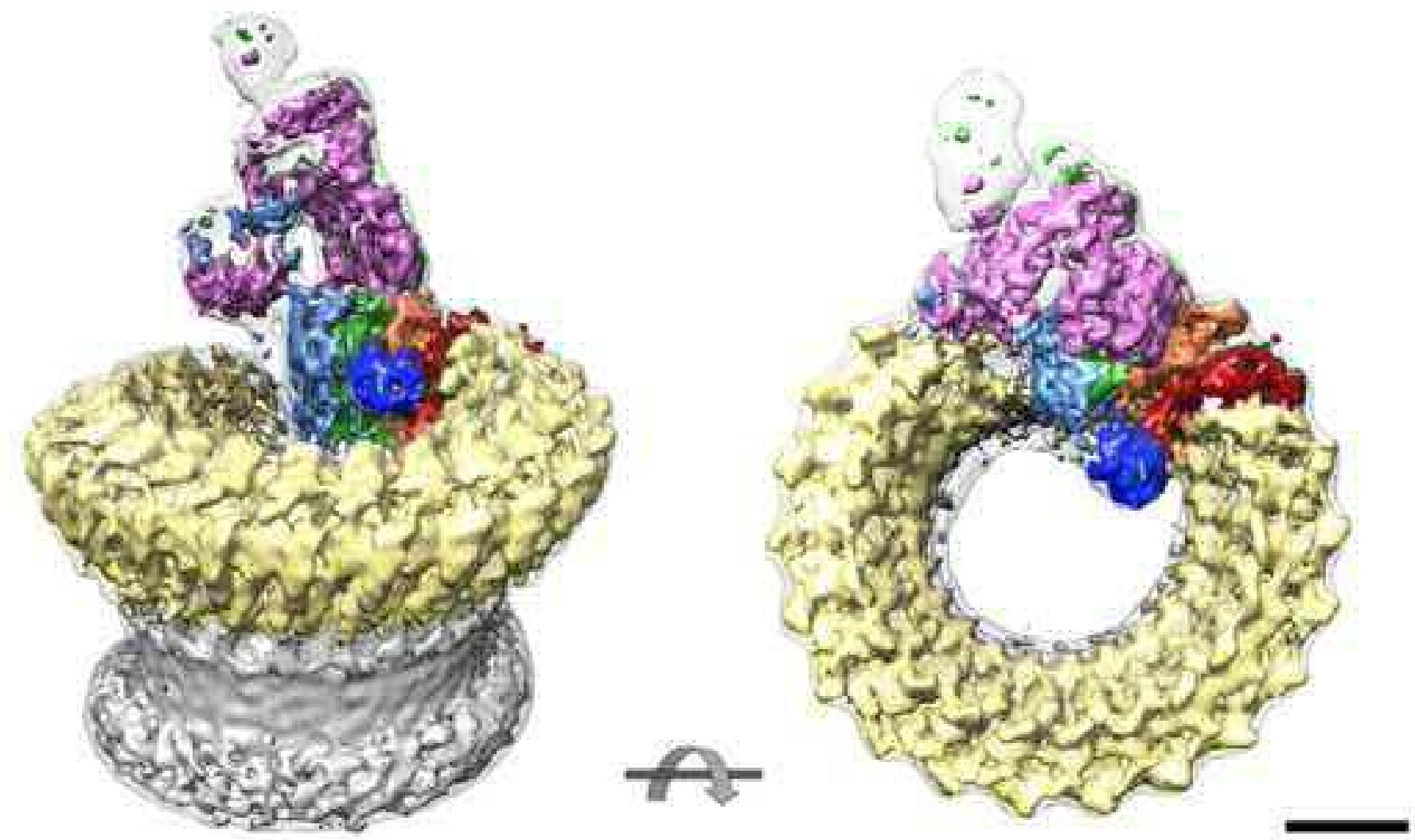

b

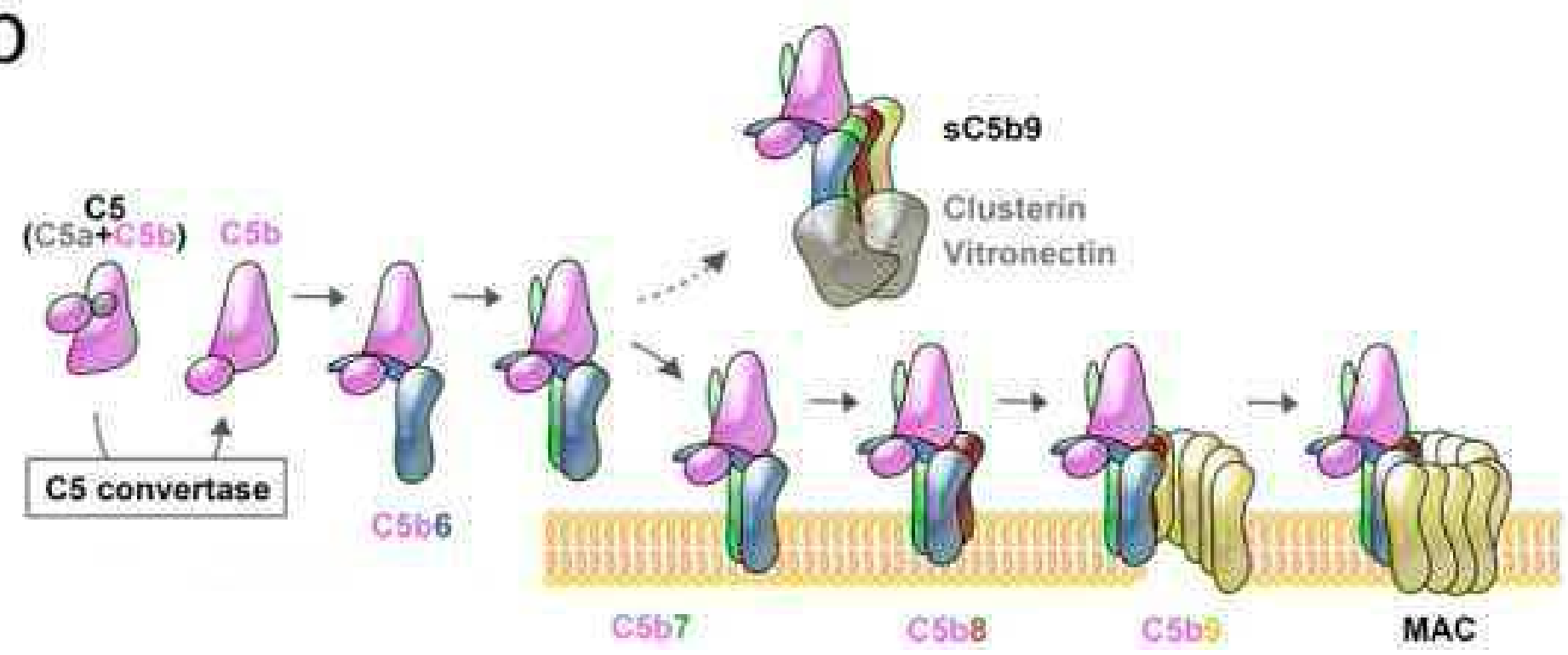

